\title{
CAN LOW RETIREMENT SAVINGS BE RATIONALIZED?
}

\author{
Jason S. Scott \\ John B. Shoven \\ Sita N. Slavov \\ John G. Watson \\ Working Paper 26784 \\ http://www.nber.org/papers/w26784 \\ NATIONAL BUREAU OF ECONOMIC RESEARCH \\ 1050 Massachusetts Avenue \\ Cambridge, MA 02138 \\ February 2020
}

We thank Hannes Schwandt and participants at the Stanford 2019 Working Longer and Retirement Conference for helpful comments. The views expressed herein are those of the authors and do not necessarily reflect the views of the National Bureau of Economic Research.

At least one co-author has disclosed a financial relationship of potential relevance for this research. Further information is available online at http://www.nber.org/papers/w26784.ack

NBER working papers are circulated for discussion and comment purposes. They have not been peer-reviewed or been subject to the review by the NBER Board of Directors that accompanies official NBER publications.

(C) 2020 by Jason S. Scott, John B. Shoven, Sita N. Slavov, and John G. Watson. All rights reserved. Short sections of text, not to exceed two paragraphs, may be quoted without explicit permission provided that full credit, including ()$^{\text {notice, }}$ is given to the source. 
Can Low Retirement Savings Be Rationalized?

Jason S. Scott, John B. Shoven, Sita N. Slavov, and John G. Watson

NBER Working Paper No. 26784

February 2020

JEL No. D14,D15,H55,J26

\begin{abstract}
$\underline{\text { ABSTRACT }}$
Simple presentations of the life cycle model often suggest a constant level of real consumption in retirement. Similarly, financial planners commonly suggest that people save for retirement in such a way as to enable them to maintain a level retirement standard of living equal to their standard of living while working. However, constant consumption with age is only optimal under the precise and unlikely condition that the subjective rate of time preference is equal to the real interest rate. Most people exhibit a positive rate of pure time preference and additionally discount the future by both mortality and morbidity risks. In comparison, the real interest rate is roughly zero percent and the term structure of interest rates suggests that this condition is likely to persist. These considerations suggest that optimal consumption in the life cycle model declines with age. This finding has major implications for optimal retirement saving. For instance, we find that for many, perhaps most, people in the bottom half of the lifetime earnings distribution, it is optimal to spend out their retirement wealth well before death and to live on Social Security alone after that. Very low earners may find it optimal to not engage in retirement saving at all.
\end{abstract}

Jason S. Scott

jscott457@yahoo.com

John B. Shoven

Department of Economics

579 Serra Mall at Galvez Street

Stanford, CA 94305-6015

and NBER

shoven@stanford.edu
Sita N. Slavov

Schar School of Policy and Government

George Mason University

3351 Fairfax Drive, MS 3B1

Arlington, VA 22201

and NBER

sslavov@gmu.edu

John G. Watson

725 Magnolia Street

Menlo Park, CA 94025

United States

jgwatson@stanford.edu 
Can Low Retirement Savings Be Rationalized?

Jason S. Scott, John B. Shoven, Sita N. Slavov and John G. Watson

\section{Introduction}

Numerous academic articles, and hundreds of stories in the popular press have been devoted to the issue of inadequate financial preparation for retirement. The general consensus seems to be that Americans are woefully unprepared for retirement (see, for example, Gomes, Hoyem, Hu and Ravina (2018)). But what does it mean to be prepared for retirement? While the particular targets may vary, "prepared for retirement" means being able to sustain a particular standard of living, corresponding to a fixed level of consumption spending, throughout retirement. The target standard of living typically corresponds to the preretirement standard of living and is expressed as a fixed percentage of pre-retirement earnings. The assumed percentage can vary, but most studies conclude that being able to replace somewhere between $65 \%$ and $85 \%$ of pre-retirement income corresponds to adequate retirement preparation. ${ }^{1}$ A recent contribution of this type is Ghilarducci, Papadopoulos and Webb (2017), who assume that the target replacement rate is 85 percent for low income individuals and 65 percent for high income people.

The desirability of a constant level of consumption is an article of faith in these studies, but it is not a necessary outcome of an economic optimization. The standard life cycle model does suggest that level consumption is optimal, but only under very specific conditions. For example, economic theory suggests that the utility from future consumption should suffer a

\footnotetext{
${ }^{1}$ The needed income is less than $100 \%$ because of lower tax rates, lower work-related expenses and no longer needing to save for retirement.
} 
discount relative to the utility from current consumption. The difficulty many individuals have delaying gratification speaks to the appropriateness of this discount. However, future consumption also can be had at a discount due to prevailing real interest rates. Only when an individual's subjective rate of time preference is perfectly offset by earned interest is steady consumption optimal.

Many factors that go into life cycle optimization suggest optimal consumption should be declining. The essential question compares the discount rate for future utility to asset returns that make future consumption cheaper. Beyond a pure rate of time preference reflecting impatience, future utility may be discounted for mortality. Survey evidence further suggests individuals attach a lower value to consumption in bad health states, particularly in states with mental impairments like dementia (Goda et al. (2015)). All of these factors push in the direction of declining consumption over the life cycle, particularly at older ages when health and mortality risks are greater and liquidity constraints no longer bind. These factors are stronger for lower wage workers, who typically face higher mortality and health risks (see, e.g., Chetty et al. 2016) and receive a Social Security benefit that replaces a relatively high percentage of their pre-retirement income.

The asset return side of the ledger has seen dramatic change over the past 10-15 years. Real interest rates have collapsed to 0 percent, and yield curves suggest this level of interest is likely to persist for decades. As we will show, even if utility discounting and asset returns previously offset each other, resulting in steady consumption, the collapse of interest rates should bring consumption forward and result in declining optimal consumption. 
Declining optimal consumption prior to and in retirement has implications for numerous financial planning topics. For example, needed savings for retirement could be dramatically lower if declining consumption is optimal. In fact, observed saving behavior is more easily understood when viewed through the lens of optimal declining consumption. Delaying Social Security may no longer be optimal even if it results in a higher expected present value of benefits, as Social Security income remains steady in real terms and one cannot borrow against future Social Security benefits. Our analysis suggests that for moderate to low income individuals living in a world of high discount rates and low interest rates, optimal consumption at older ages should be declining, assets accumulated for retirement should be relatively low, and full reliance on Social Security should occur fairly early in retirement. Our analysis should not be interpreted as a recommendation to individuals, who must consider numerous other factors that are not captured in our stylized life cycle model. Rather, we derive a set of conditions under which low saving can be rationalized within a life cycle model.

The rest of this paper is organized as follows. In Section 2, we review the literature on optimal consumption paths in life cycle models. In section 3, we solve a standard life cycle model and explore its implications for the optimal path of consumption. In Section 4, we motivate relevant parameters for the three main discount factors driving consumption: time, mortality and health. In Section 5, we consider the impact of these parameters on the pattern of optimal consumption. In Section 6, we consider the impact of optimal declining consumption on Social Security claiming behavior and demand for private annuities. Section 7 summarizes our conclusions and mentions areas for further exploration of this topic. 


\section{Literature on Optimal Consumption Paths}

In the standard life cycle model, individuals maximize utility by smoothing consumption over their lifetime, given their preferences and the relative prices of current and future consumption (Friedman 1957; Modigliani 1966). While consumption smoothing avoids sharp jumps in consumption, it does not necessarily imply steady consumption. The slope of optimal consumption over the lifetime depends on the difference between the interest rate and the subjective rate of time preference. Additional features have been added to the basic life cycle model to better fit the data (see Attanasio and Weber (2010) for a review); for example, Shefrin and Thaler (1988) add features from behavioral economics to account for less-than-perfect rationality. There is also a literature relating standard financial planning advice to the life cycle model (see e.g., Kotlikoff (2006); Scholz and Seshadri (2009); Scott et al. (2019)). Most relevant to our work in this paper, financial planning often relies on a target replacement rate, or ratio of post-retirement to pre-retirement income. However, that assumption can be at odds with the predictions of a life cycle model. For example, Scholz and Shshadri (2009) use a life cycle model to show that optimal replacement rates can vary greatly across the population and are often not consistent with the standard range of replacement rates used in financial planning. Scott et al. (2019) show that the target replacement rate should be adjusted in response to low returns and low wage growth. This paper contributes to that literature by showing that declining consumption during retirement, not the steady consumption implied by a target replacement rate, may be optimal for most individuals.

Many papers in the life cycle consumption literature examine the pattern of saving, income and consumption during working years. Not many examine these patterns during 
retirement years, and only a few papers especially emphasize the possibility that declining consumption with age may be optimal, or that exhausting financial assets well in advance of death can be part of the optimized plan as well. One such set of papers focuses on the so-called "hump shaped" profile of optimal consumption. Gourinchas and Parker (2002) is representative of this set of papers, and their results suggest that optimal consumption (adjusted for family size) begins to fall at roughly age 45 . Relatedly, the authors estimate the pure rate of time preference to be between 4.0 and 4.5 percent, the degree of risk aversion to be between 0.5 and 1.4 and the real, safe after-tax interest rate to be 3.44 percent. Therefore, the degree of impatience exceeds the market return to patience (the real interest rate). Part of what makes our paper valuable is that the real interest rate since 2009 has been roughly zero percent and financial markets are forecasting that extremely low interest rates are here to stay for the long haul. Banks, Blundell, Levell and Smith (2019) establish empirically that consumption declines in both the United Kingdom and the United States after age 60, even before the dramatic decline in real interest rates that occurred in 2009. Presumably, the observed negative slopes would be steeper in the current zero real interest rate environment. ${ }^{2}$

The two papers closest to ours are Hurd (1989) and Hammermesh (1984). Hammermesh (1984) examines consumption early in retirement using the first two waves of the Retirement History Study from the early 1970s. He finds that consumption in the year or

\footnotetext{
${ }^{2}$ Another literature has been concerned with changes in consumption at the time of retirement. The life cycle framework implies that consumption does not change with respect to anticipated changes in income. Early papers in this literature such as Bernheim, Skinner and Weinberg (2001) and Hurd and Rohwedder (2003) found that consumption dropped discontinuously at the time of retirement, in contradiction to the life cycle hypothesis. Later studies, such as Hurd and Rohwedder (2006) and particularly Hurst (2008) found that the earlier work had relied too much on food consumption, both at home and away from home, and transportation costs. With more comprehensive consumption data, Hurst finds that the discontinuity at retirement largely disappears. This work is only tangentially related to our work.
} 
two immediately after retirement tends to exceed sustainable consumption, obtained by annuitizing all financial wealth and adding Social Security benefits. He also observes that consumption declines on average 5 percent per year for the same people in the two interview waves, two years apart. He concludes that the most likely cause of the observed decline in consumption is that for many people the subjective rate of time preference is substantially higher than the real interest rate. That is, declining consumption is actually optimal for many in his data set.

While the Hammermesh contribution is primarily empirical, Hurd (1989) lays out a theoretical continuous time life cycle model in a very similar manner to the discrete time version of this paper. He concentrates on the impact of mortality risk and bequest motives on the optimal consumption path for retirees. In his primary estimation, which uses the 19691979 Retirement History Study, he finds that optimal consumption declines fairly rapidly in retirement. He assumes a 3 percent real interest rate and estimates the pure rate of time preference to be roughly 5 percent. His primary estimate of the degree of risk aversion is quite low, namely about 0.73 . His estimates indicate that for most people the utility value of leaving a bequest is quite low. He finds that for many people it is optimal to spend down bequeathable wealth in the first few years of retirement and live on Social Security or other annuities thereafter. This is consistent with our results.

There are several new aspects to this paper. First, we don't presume that everyone has the same rate of time preference (impatience). However, with after tax, safe, real interest rates being zero, essentially everyone would seem to prefer higher consumption earlier in life and lower consumption later. This negatively sloped optimal consumption path means that it takes 
less wealth at retirement to fund the optimal life cycle plan. Second, like Hurd (1989) we incorporate mortality risk, but using recent cohort life tables from Social Security which generally have substantially reduced age-specific mortality risks relative to those assumed by

Hurd. Third, we introduce the possibility that certain health outcomes, particularly dementia, may involve lower utility from a given consumption bundle. The incidence of dementia at very old ages is quite high and this alone may reduce the attractiveness of saving money for these situations. Finally, we concentrate on the lower half of the lifetime earnings distribution. For those in this part of the distribution, Social Security provides a higher replacement of earnings in retirement. This group in particular may find it optimal to save less in the face of zero interest rates and relatively generous annuitized Social Security benefits.

\section{Standard Life-Cycle Model and Consumption Trajectories}

To illustrate the factors contributing to the optimal consumption pattern, consider the following standard life cycle utility function:

$$
V=\sum_{t=0}^{T} \alpha_{t} \cdot U\left(C_{t}\right)
$$

In this formulation, utility each year $U\left(C_{t}\right)$ derived from consumption in that year, $C_{t}$, and is discounted by a time specific factor, $\alpha_{t}$. Here, $U(C)$ is the felicity function. This time-specific discount rate captures factors that differentially affect consumption based expected utility. We consider a discount factor with three components, time, mortality and health status:

$$
\alpha_{t}=e^{-\delta t} \cdot S_{t} \cdot \theta_{t}
$$


Our time discount factor, $e^{-\delta t}$ captures the fact that later consumption is less desirable than earlier consumption. $S_{t}$ is the probability of survival for t years given being alive initially. The idea here is that as the likelihood of mortality increases, the individual finds it more and more difficult to justify setting aside scarce resources to fund spending in years where survival is less and less certain. Finally, we have a health status factor, $\theta_{t}$, reflecting a discount to future utility that reflects the possibility of having a health impairment that reduces the value of consumption. Similar to mortality, this factor captures a possible preference that favors spending in younger states that are likely to be relatively free of physical or mental impairments. We assume $\theta_{t}=1$ if the individual anticipates being healthy (or receiving the same utility from consumption regardless of health), and $\theta_{t}<1$ if the individual anticipates a risk of having an impairment that reduces the value of consumption.

Wealth evolves via the following equation of motion:

$$
A_{t+1}=\left(A_{t}+B_{t}-C_{t}\right) \cdot R_{t}
$$

Here we have assets, $A_{t}$; Social Security benefits and income, $B_{t}$; consumption, $C_{t}$; and a gross return, $R_{t}$. Before optimization can occur, we must discipline consumption with a budget constraint. In the simple model, we constrain consumption by requiring assets to be nonnegative, $A_{t} \geq 0$, and ending wealth to be zero, $A_{T+1}$. Later we will relax this constraint to consider borrowing. Finally, we choose a CRRA utility function with risk aversion parameter, $\gamma$, as the felicity function.

To illustrate the optimal consumption trajectory, consider a simple case where an individual begins with initial wealth, but never receives additional income, i.e. $B_{t}=0$ for all $t$. Optimal consumption is then 


$$
C_{t}=\kappa_{t} \cdot C_{t-1}
$$

where

$$
\kappa_{t}=\left(R_{t} \frac{\alpha_{t}}{\alpha_{t-1}}\right)^{1 / \gamma}
$$

As evidenced by the above equation, there are three factors at play in determining the path of optimal consumption. On the plus side, delaying consumption allows one to earn a return that facilitates additional consumption. On the downside, that additional consumption is enjoyed in a relatively inferior state captured by the ratio of annual discount rates. If the product of these factors exceeds one, then optimal consumption is upward sloping through time. If less than one, consumption declines. Only in the special circumstance where these factors exactly offset is consumption constant. This formulation also illustrates the role of risk aversion. When viewed across time, increasing or decreasing consumption counts as disperse consumption that is undesirable for a risk-averse agent. As risk aversion increases, the ratio of future consumption to current consumption tends towards unity. Infinite risk aversion is also sufficient to ensure constant consumption.

To get an idea of the magnitude of potential optimal consumption decline, we need more specifics on the parameter choices. We model the gross return from $t-1$ to $t$, $R_{t}$, is:

$$
R_{t}=e^{r} \frac{\underline{S}_{t-1}}{\underline{S}_{t}}
$$

Where $\underline{S}_{t}$ is the survival rate appropriate for annuity pricing. Note, we can model the absence of a functioning annuity market by assuming $\underline{S}_{t}=1$ for all $t$. The ratio of the survival rates reflects the annual mortality relevant for pricing between period t-1 and t. Combining (1), (2), and (3) yields the Euler equation 


$$
C_{t}=\left(e^{(r-\delta)} \frac{\underline{S}_{t-1} \cdot S_{t} \cdot \theta_{t}}{\underline{S}_{t} \cdot S_{t-1} \cdot \theta_{t-1}}\right)^{1 / \gamma} \cdot C_{t-1}
$$

The recursive nature of (4) and cancellation yields ${ }^{3}$ :

$$
C_{t}=\kappa_{t} \cdot \kappa_{t-1} \cdot \kappa_{t-2} \cdots \kappa_{1} \cdot C_{0}=\left(e^{(\mathrm{r}-\delta) t} \cdot \frac{S_{t}}{\underline{S}_{t}} \cdot \theta_{t}\right)^{1 / \gamma} \cdot C_{0}
$$

To gain intuition as to the importance of these various factors, consider optimal consumption of an individual that sets up a plan at age 65. Assuming interest rates equal the individual's time discount, $r=\delta$, annuity markets are functioning and perfectly compensate for mortality risk, $\underline{S}_{t}=S_{t}$ and the prospect of poor health does not impact wealth allocation, $\theta_{t}=1$, then consumption at age 85 equals consumption at age 65 . Now consider what happens to optimal consumption at age 85 as we change these assumptions. For example, suppose the annual time discount rate exceeds the interest rate by 3 percent. Assuming a risk aversion parameter of 3 , optimal consumption 20 years into retirement then becomes:

$$
C_{20}=\left(e^{(r-\delta) 20}\right)^{1 / \gamma} \cdot C_{0}=\left(e^{-0.6}\right)^{1 / 3} \cdot C_{0}=0.82 C_{0}
$$

If we further assume the survival probability to age 85 is $50 \%$, and assume a lack of relevant annuity markets, $\underline{S}_{20}=1$, then optimal age 85 consumption drops to $65 \%$ of initial retirement consumption. Adding a discount to utility reflecting the possibility of incapacitation by age 85 , $\theta_{20}=0.7$, drops optimal age 85 consumption down to $58 \%$ of initial consumption. It is important to note that risk aversion plays a large role in maintaining high levels of optimal consumption late in retirement. In his seminal paper, Hurd (1989) argues for a much lower risk

\footnotetext{
${ }^{3}$ Note, this assume the individual is currently alive $\left(\underline{S}_{0}=S_{0}=1\right)$ and healthy $\left(\theta_{0}=1\right)$.
} 
aversion parameter than often considered in the literature. He has two separate estimates of $\gamma$, namely 0.73 and 1.12 . Assuming this level of risk aversion implies optimal consumption is much more responsive to mortality and health risk. In these three cases, changing the assumed risk aversion parameter to 1.0 shifts optimal consumption at age 85 from $82 \%, 65 \%$ and $58 \%$ to $59 \%, 32 \%$, and $23 \%$, respectively. Needless to say, if optimal consumption at age 85 is less than $50 \%$ of consumption at age 65 , many assumptions regarding retirement and retirement readiness need to be re-examined.

\section{Discounting the future}

In this section, we explore the various factors that could contribute to optimal declining consumption in retirement. Three factors argue for declining consumption in retirement: time, mortality and health.

\section{a. Time: Time discount $(\boldsymbol{\delta})$ vs. interest rates ( $\mathbf{r})$}

In our life cycle model, we separately consider the pure rate of time preference, $\delta$, and the potential reductions in future utility from mortality and morbidity. A key factor in the pattern of optimal consumption over time is the difference between $\delta$ and $r$, the real safe rate of interest. The intuition is that $\delta$ represents time preference or the amount of impatience that an individual or household exhibits and $r$ represents the real return for patience offered in financial markets. If $\delta>r$, then shifting consumption from the future towards the present may increase lifetime utility, whereas the opposite is true in the case where $\delta<r$. With $\delta>r$, the optimal allocation would have the marginal utility of consumption increasing over time, meaning that consumption would decrease with age. 
There is no reason to assume that everyone exhibits the same rate of time preference, $\delta$. For many years researchers have tried to uncover $\delta$ by asking a sample of people whether they would prefer $\$ 100$ immediately or $\$ Y$ one year in the future. Through a series of such questions, researchers try to find the point of indifference for each person interviewed. An early example of this approach was Fuchs (1982), whereas more recent examples include Huffman, Maurer and Mitchell (2016) and Goda, Levy, Manchester, Sojourn and Tasoff (2015). These studies tend to find surprisingly high rates of time preference. For instance, the average rate of time preference found by Huffman, Maurer and Mitchell (HMM) in a special supplement to the 2014 wave of the Health and Retirement Study (HRS) was 54 percent for their sample of individuals over 70 (the median was 58 percent). The answers presumably combine the effects of impatience, mortality and morbidity. The cumulative distribution of personal discount factors found by HMM is shown here as Figure 1 . Note that roughly 80 percent of those interviewed displayed discount factors greater than 20 percent, with roughly 60 percent having discount factors exceeding 40 percent. While these results are higher than the rest of the literature based on these experimental questionnaires, probably because the sample population is much older, it is common for the mean personal discount factor to be 25 percent or more. 
Figure 1. Cumulative Distribution of Measured IRR Values for Older (70+) HRS Respondents

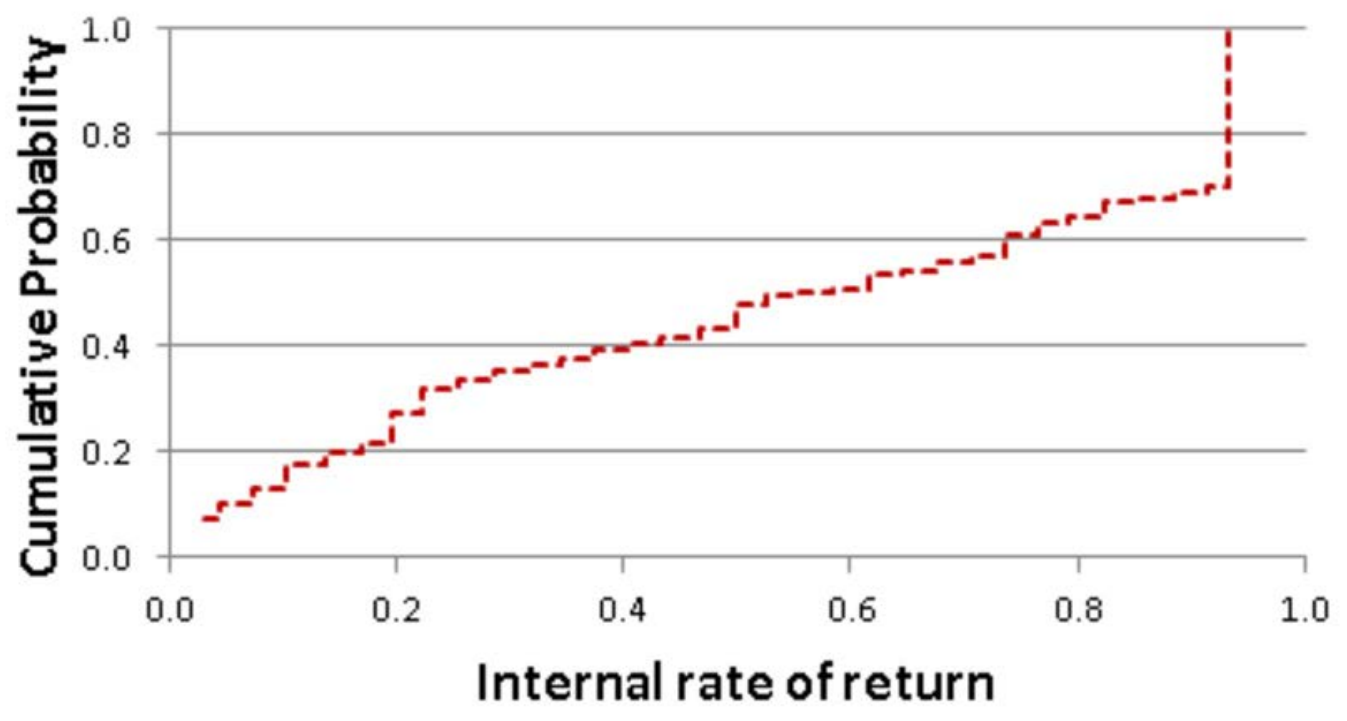

The validity of this type of study can be challenged as the questions are hypothetical and even the hypothetical stakes are usually low, such as $\$ 100$. Still, the results are consistent with other non-experimental studies, all of which find most people have discount factors far greater than the interest rate. For example, Hausman (1979) who examined the choices consumers made between appliances of varying energy efficiency. He found the effective discount rate applying to the energy saving of more expensive and efficient appliances was roughly 20 percent.

Warner and Pleeter (2001) examine the choices of 66,000 U.S. military personnel (55,000 enlistees and 11,000 officers) who were offered two distinct severance packages - a lump sum or an annuity - in 1992-3 as part of the downsizing of the services following the 
collapse of the Soviet Union. ${ }^{4}$ The annual rate of discount that equated the present value of the annuity offer with the lump sum offer ranged from 17.5 to 19.8 percent. The annuity was not inflation adjusted, so this internal rate of return discount rate should be thought of as a nominal rate of return. This was in an era of roughly 3 percent inflation and Treasury-Bill interest rates were in the 3.5 to 5 percent range. The real interest rate was thus 0.5 to 2.0 percent and the real return on the annuity was roughly 16 percent. With these choices, more than 90 percent of enlisted personnel chose the lump sum offer, as did more than half of the officers. The authors estimate that the average personal discount factor of enlisted personnel was between 35 and 50 percent. The modal education level of the enlistees was high school graduate, whereas the vast majority of officers were college graduates.

Simon, Warner and Pleeter (2015) examined another choice faced by members of the military. The choice was whether to stay with a less generous pension plan and accept $\$ 30,000$ cash or switch to the newly available more generous pension annuity. The choice was faced by a particular cohort of military members with 15 years of service and dealt with the pension plan that they would enjoy at the 20-year mark.

Even though the typical "money earlier or later" study finds quite high personal discount rates, there are reasons to question whether this implies a high rate of time preference, $\delta$. Conceptually, the rate of time preference is a discount applied to "utils" enjoyed further in the future relative to utils enjoyed closer to the present. In our model and in the classic life cycle

\footnotetext{
${ }^{4}$ One choice was a lump sum amount of 15 percent of annual base salary times the number of years of service (YOS) and the other was an annuity equal to 2.5 percent of base pay times YOS payable annually for two times YOS. For example, a Sargent in the Army making $\$ 35,000$ in today's dollars with 10 years of service would have the choice between a lump sum of $\$ 52,500$ and twenty annual payments of $\$ 8,750$.
} 
model, utility at time $t$ depends on consumption at that time. But, these studies are not about utility and most of them are not about consumption. They are about money received at different points in time. The implicit assumption is that the incremental money will be consumed when received and current utility will go up proportionately. But, of course, that is not the optimal thing to do with an injection of money at a point in time in a life cycle framework. The connection between the preference for money sooner rather than later and the rate of time preference $\delta$ is typically not dealt with explicitly in the experimental studies. The recent paper by Cohen, Ericson, Laibson, and White (2016) thoroughly examines these issues. To quote them, "the literature is in discord."

We think that there is substantial evidence of considerable impatience. However, we don't think the evidence pins down the right value or values for $\delta$ in our model. Therefore, we follow the common practice of looking at a range of values. Our base case will be a value of $\delta$ of .03 and we will also report results for this rate of time preference being 5 percent or 10 percent. Our argument regarding the optimality of declining consumption would be even stronger at higher rates, so we view our assumptions as conservative.

The real interest rate, $r$, in our model is easier to pin down. It should reflect the expected real, safe interest rate over the long-run future, so basing it on $r$-star, the natural rate of interest, seems appropriate. The natural rate of interest is the real, short-term interest rate that is neither expansionary nor contractionary. We discuss it at some length in Scott, Shoven, Slavov and Watson (2019). One of the most prominent estimates of r-star is by Laubach and Williams (2003) and they update their estimates quarterly. John C. Williams, one of the authors, is now the President of the New York Federal Reserve Bank. Figure 2 shows the most 
recent Laubach and Williams's estimates, through 3/31/2019. It shows that the natural rate of interest has hovered in the 0.5 to 0.75 percent range for the past eight years.

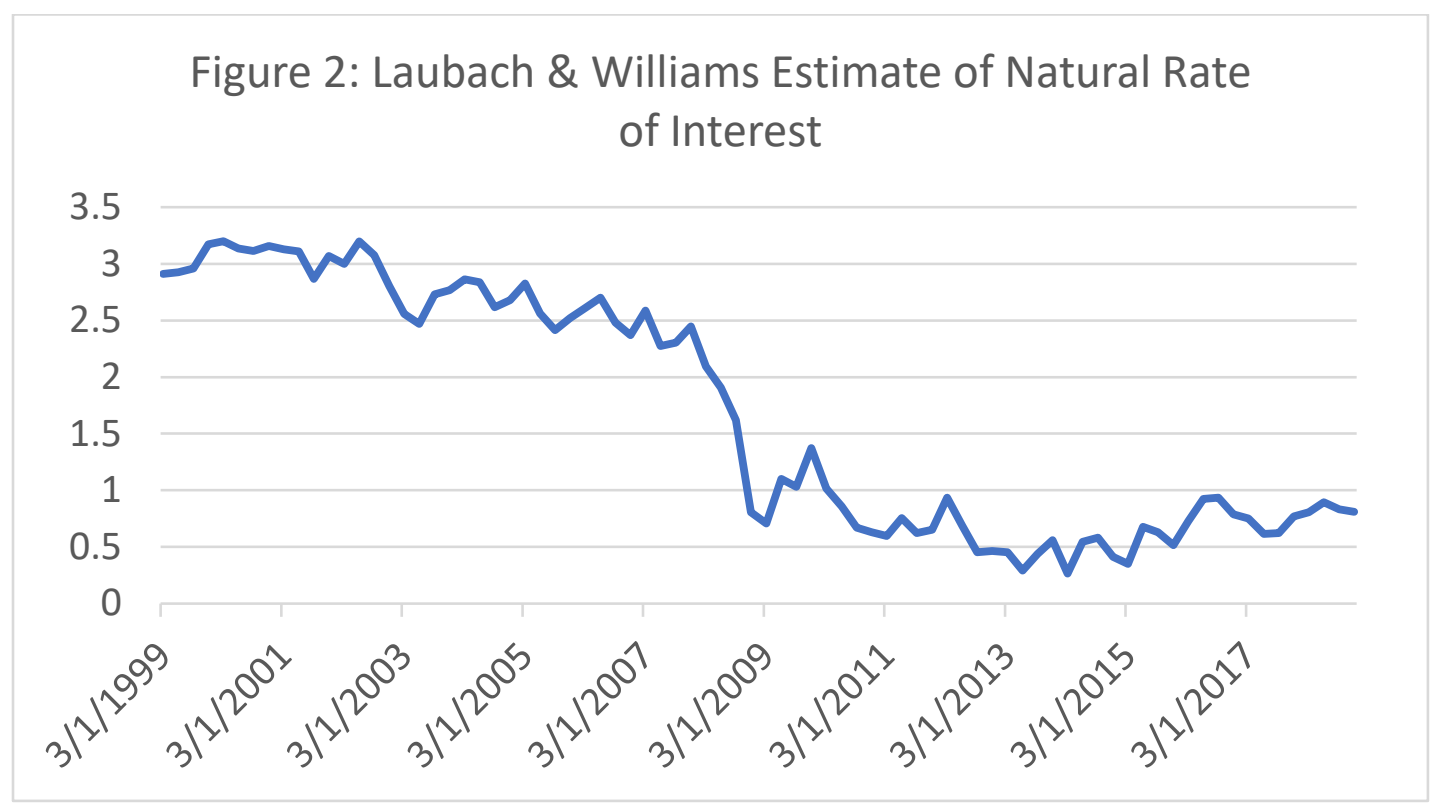

We want to emphasize that these are not actual inflation-adjusted Treasury-bill rates, which were negative through much of this period, but the estimate of the policy neutral real rate. We believe that these are the best forecast for real short rates over the medium to long-run horizon. The typical retirement saver could only access these rates through a money market mutual fund that would have expense ratios in this same 0.5 to 0.75 percent range, leaving the net real yield approximately zero. Unsophisticated investors, who save via bank deposits, would do significantly worse, with negative lending rates. With all this in mind, we will set $r$, the real, safe short rate in the future at zero for our calculations and that means that the three cases we examine for $\delta-r$ are $.03, .05$ and .10 .

\section{b. Mortality: Individual mortality discount (S) vs. Annuity discount $(\overline{\mathbf{S}})$}


Balancing consumption today and future consumption logically involves considering the likelihood of survival. According to Social Security Administration cohort mortality projections, a male born in 1964 has a roughly 50 percent probability of living to age 85; the corresponding probability for females is roughly 61 percent. ${ }^{5}$ However, mortality varies across the population depending on birth cohort, as well as characteristics such as education, gender, income, and race. For example, Chetty et al. (2016) document that, at age 40, high-income individuals have higher life expectancy than low-income individuals, and that this gap has been widening over time. Brown, Liebman, and Pollet (2002) provide ratios of age-specific mortality rates for individuals in different education and race groups. For example, at age 62 , white men with less than a high school education have an age-specific mortality rate that is roughly 30 percent greater than average, and black men with a high school education or less have an age-specific mortality rate that is almost twice the average.

The Health and Retirement Study (HRS), a nationally representative panel survey of the U.S. population aged 50 and older asks individuals to provide subjective estimates of their mortality and life expectancy, as well as a subjective assessment of their health. Previous research suggests that these subjective measures are correlated with actual mortality (e.g., Delavande and Rohwedder 2011; Siegel, Bradley, and Kasl 2003). Moreover, decisions such as labor supply and Social Security claiming appear to be related to subjective mortality (e.g., Hurd, Smith, and Zissimopoulos 2004). Thus, it is reasonable to assume that individuals accurately assess their mortality risks and behave accordingly.

\footnotetext{
${ }^{5}$ These calculations are based on the cohort mortality tables underlying the 2013 Trustees Report.
} 
Length-of-life risk can be hedged by the purchase of annuities, which guarantee a fixed level of income (either real or nominal) for the remainder of one's life. A large literature documents a phenomenon known as the "annuity puzzle," whereby individuals do not purchase annuities even though standard life cycle models suggest that they raise lifetime utility for riskaverse individuals (e.g., Yaari 1965; Mitchell, Poterba, Warshawsky, and Brown 1999; Warner and Pleeter 2001).

One possible explanation for the annuity puzzle is that commercially available annuities are subject to adverse selection. That is, individuals who buy annuities tend to have longerthan-average life expectancies, which raises annuity prices and reduces demand. Mitchell, Poterba, Warshawsky, and Brown (1999) show that even with actuarially unfair pricing, annuities raise lifetime utility. Moreover, a large literature has shown that individuals decline to purchase even actuarially advantageous annuities. Specifically, delaying Social Security claiming is equivalent to buying an annuity; those who delay forgo benefits now in exchange for higher benefits for life. Even though this annuity is actuarially advantageous for most singles and primary earners (see, e.g., Meyer and Reichenstein 2010, 2012; Sass, Sun, and Webb 2013; and Shoven and Slavov 2014a, 2014b), delaying Social Security beyond full retirement age is rare (see, e.g., Goda, Shoven, and Slavov 2018). Survey evidence suggests that people would be more willing to delay Social Security if they could receive the gains from delay as an actuarially fair lump sum rather than an annuity (Maurer, Mitchell, Rogalla, and Schimetschek 2018).

Overall, the evidence suggests that people accurately assess their mortality risks and behave accordingly. It also suggests that annuitizing income is not a popular strategy when 
annuities are subject to adverse selection and may remain unpopular even if actuarially fair or advantageous annuities were available.

\section{c. Health Dependent Utility}

Previously, little research has considered the question of how health impacts utility. However, individuals could reasonably question why they should set aside resources to fund consumption in states where they may or not derive much utility from those resources.

Dementia and other impairments can cause permanent institutionalization. In this section, we explore the plausible implications for health dependent utility, or equivalently, what is the appropriate assumption for $\theta_{t}$ ?

Our model utilizes an expected utility framework. We are adding up probability weighted utility to derive overall utility. When dealing with mortality, we took utility to be the probability of being alive, $S_{t}$, multiplied by the utility generated from consuming $C_{t}$. In principle, there is a utility term associated with the probability of being dead at time $t, 1-S_{t}$, but this term is left out of the utility owing to our assumption that there is no bequest motive.

For health, we take a similar expected utility approach, only here both healthy and unhealthy states contribute to the overall utility function. The discount for health-dependent utility is modeled as:

$$
\theta_{t} \cdot U_{t}(\cdot)=Q_{t} \cdot \theta_{g} \cdot U_{t}(\cdot)+\left(1-Q_{t}\right) \cdot \theta_{p} \cdot U_{t}(\cdot)
$$

Where $\mathrm{Q}_{\mathrm{t}}$ is the probability of good health during year $\mathrm{t}, \theta_{g}$ is the utility multiplier for good health, and $\theta_{p}$ is the utility multiplier for poor health. $U_{t}(\cdot)$ captures all the non-health related 
utility terms. We normalize good health as the base case $\left(\theta_{g}=1\right)$, implying our parameter for health dependent utility is:

$$
\theta_{t}=Q_{t}+\left(1-Q_{t}\right) \cdot \theta_{p}
$$

While estimates of the probability of poor health are readily available, the utility discount associated with poor health has not received much attention. However, a recent paper (Brown et. al. 2013) provides sufficient information to formulate an estimate. In this paper, a representative sample of individuals are asked to imagine there is an even chance that they are in good or poor health at age 80 . They are then asked to how they would allocate a $\$ 10,000$ windfall between those two possibilities. Would they prefer to have all, most, some or none of the windfall in the healthy or unhealthy state? Of interest for our work is that the answers, while volatile, tended to allocate wealth between the unhealthy and healthy outcome at an approximately $1: 2$ ratio.

Using our assumed CRRA utility function, we can translate this wealth allocation ratio into an estimate for $\theta_{p}$ :

$$
\theta_{p}=\left(\Delta_{p} / \Delta_{g}\right)^{\gamma}=(1 / 2)^{\gamma}
$$

Where $\Delta_{p}$ and $\Delta_{g}$ represent the incremental wealth allocated to the poor and good health state, respectively. Note the impact of risk aversion on the estimate of $\theta_{p}$. If risk aversion is 1 , $\theta_{p}$ is 0.5 . However, if risk aversion is instead much higher at 3 , then $\theta_{p}$ is 0.125 . When deciding how to allocate incremental wealth, a high level of risk aversion argues for a more even split. If individual choose a large wealth disparity, then they must either be highly risk tolerant or greatly discount utility in the unhealthy state. Throughout this paper, we will assume a $\theta_{p}$ consistent with the risk aversion assumption under analysis. 


\section{Declining Consumption and Optimal Retirement Savings}

In this section, we consider the impact of more reasonable discounting assumption on the optimal accumulation of assets and consumption trajectory.

\section{a. Worker Earnings and Replacement Rates}

The Social Security Administration publishes income replacement projections for hypothetical workers (Clingman et. al. 2019). This analysis tracks five prototypical workers, each with a different assumed earning profile. For our analysis, we consider the three lower earning profiles analyzed by the SSA: Very Low Earnings, Low Earnings and Moderate Earnings. These profiles are defined as earnings that track $25 \%, 45 \%$ and $100 \%$, respectively, of the average wage index (AWI). ${ }^{6}$ The SSA projects that the income replacement rate for a Moderate earning worker who is age 55 in 2020 is $40.5 \%$ assuming the worker claims Social Security at their full retirement age of 67. Replacement rates for Very Low and Low earning profiles are $75 \%$ and $54 \%$, respectively. We assume from a worker perspective that all earned income is subject to a payroll tax and all Social Security income is tax free. The resulting after tax replacement rates for Moderate, Low and Very Low earning workers are: $43.2 \%, 57.6 \%$ and $80.0 \%$, respectively.

\section{b. Consumption and asset profiles for Moderate Earning workers}

\footnotetext{
${ }^{6}$ The AWI in 2019 is $\$ 53,864.25 \%$ and $45 \%$ of $A W I$ is $\$ 13,466$ and $\$ 24,239$, respectively.
} 
To illustrate the impact of discounting on consumption and saving decisions, consider a Moderate Earning worker. We will initially assume this person arrives at age 55 with zero net savings, and has twelve years pre-retirement to begin saving in earnest. We normalize annual pre-retirement income to $\$ 100$, so in this case income from age 55 to age 66 is $\$ 100$, and income from age 67 onwards is $\$ 43.20$. Under this normalization, all dollar values can be interpreted as a percent of pre-retirement income. Our baseline case assumes an individual that has a time discount of 3 percent and can earn a 3 percent real return on assets $(r=\delta=3 \%)$. For mortality discounting, we assume this individual is female, and has access to annuity markets that fully compensate her for her mortality $(S=\underline{S})$. Finally, we examine a risk aversion parameter of one, $\gamma=1$, which is roughly in line with the findings of Hurd (1989).

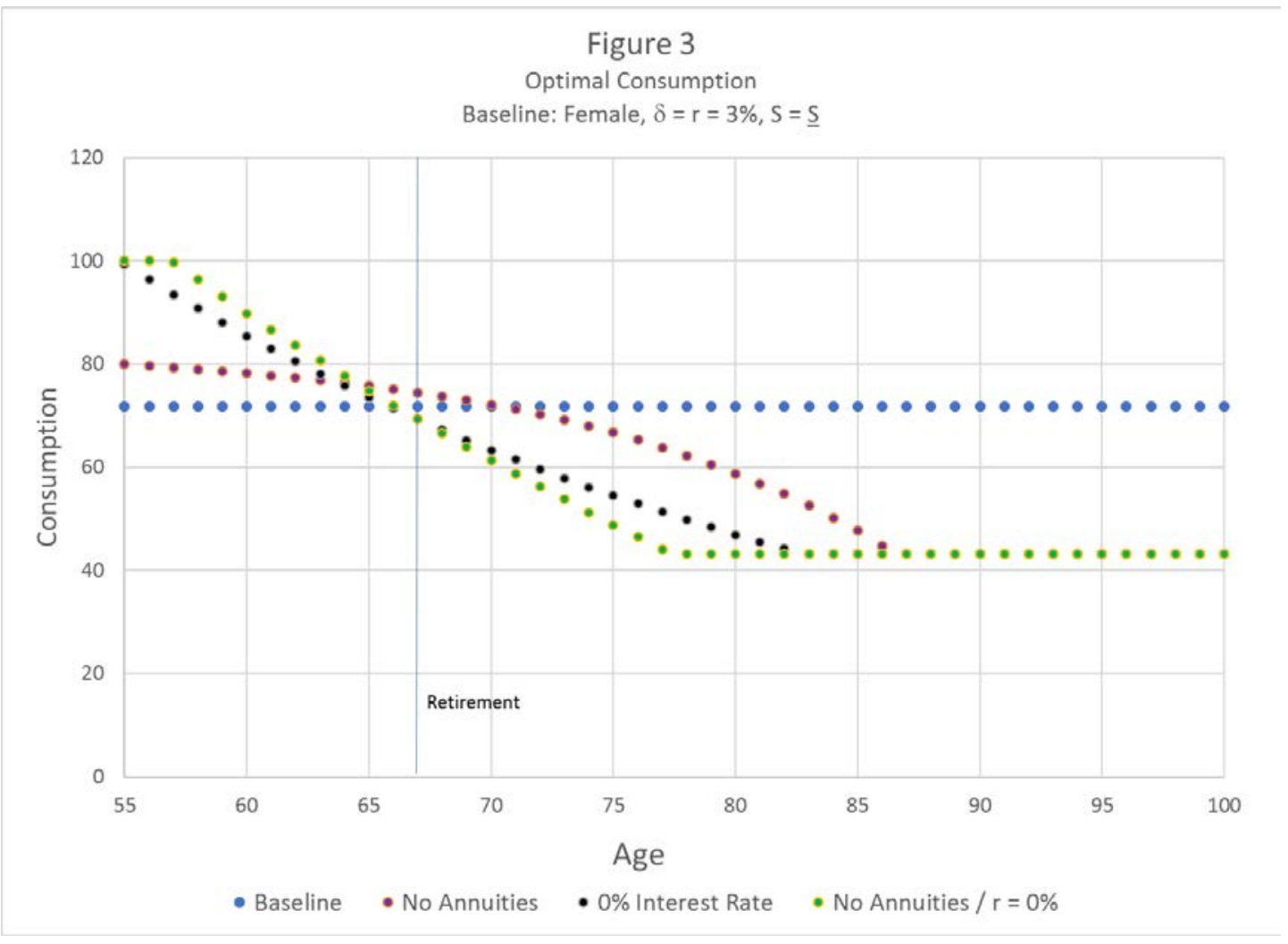


Figure 3 illustrates the results of this baseline analysis. Because all discounting is perfectly offset by investment returns, there is no preference to shift consumption either earlier or later, and consumption is perfectly level at approximately $\$ 71.73$ (i.e. 71.73 percent of pre-retirement earnings).

The second scenario we consider eliminates annuities from the analysis. In the absence of annuities, mortality discounting drives a desire for declining consumption. However, because mortality is fairly low at early ages, the effects on spending are more pronounced at older ages. In this case, initial spending at age 55 is $\$ 80.08$. Spending at age 67 is $\$ 74.48$, representing a modest $7 \%$ reduction compared to initial spending. Unlike the baseline case, assets are eventually exhausted, and at ages 87 and above all consumption is fully reliant on Social Security $(\$ 43.20)$.

The third scenario allows annuities but assumes that the prevailing real interest rate is zero percent. This change has a large effect on spending pre-retirement. Initial spending at age 55 is substantially higher at $\$ 99.32$. Moreover, spending declines more rapidly, so that by retirement age, spending is $\$ 69.29$, reflecting a $30 \%$ reduction in over that time frame. In this case, all assets are exhausted four years earlier at age 83.

The fourth scenario combines both assumptions and assumes real interest rates are zero and individuals are unable to capture a mortality credit on their investments. This combination results in an even higher initial spending of $\$ 100$, and a steeper decline in spending. Because spending equals pre-retirement income, the borrowing constraint binds. An individual who did not face a borrowing constraint would increase initial consumption above $\$ 100$ and carry a negative asset balance forward, allowing consumption at age 56 to fall below 
consumption at age 55. The presence of the borrowing constraint results in flat consumption at ages 55 and 56.

Figure 4 reports on the same four scenarios, but tracks asset balances instead of annual consumption. The impact of discounting on saving levels is sizeable. For the baseline case, the individual accumulates $\$ 434$ (434\% of pre-retirement income) at retirement. The 'no annuities' case lowers accumulated assets at retirement to $\$ 322$. Assuming 0 percent interest lowers accumulated assets to $\$ 190$, and finally, employing both assumptions drops accumulated assets at retirement all the way to $\$ 145$, or roughly one-third of the baseline case.

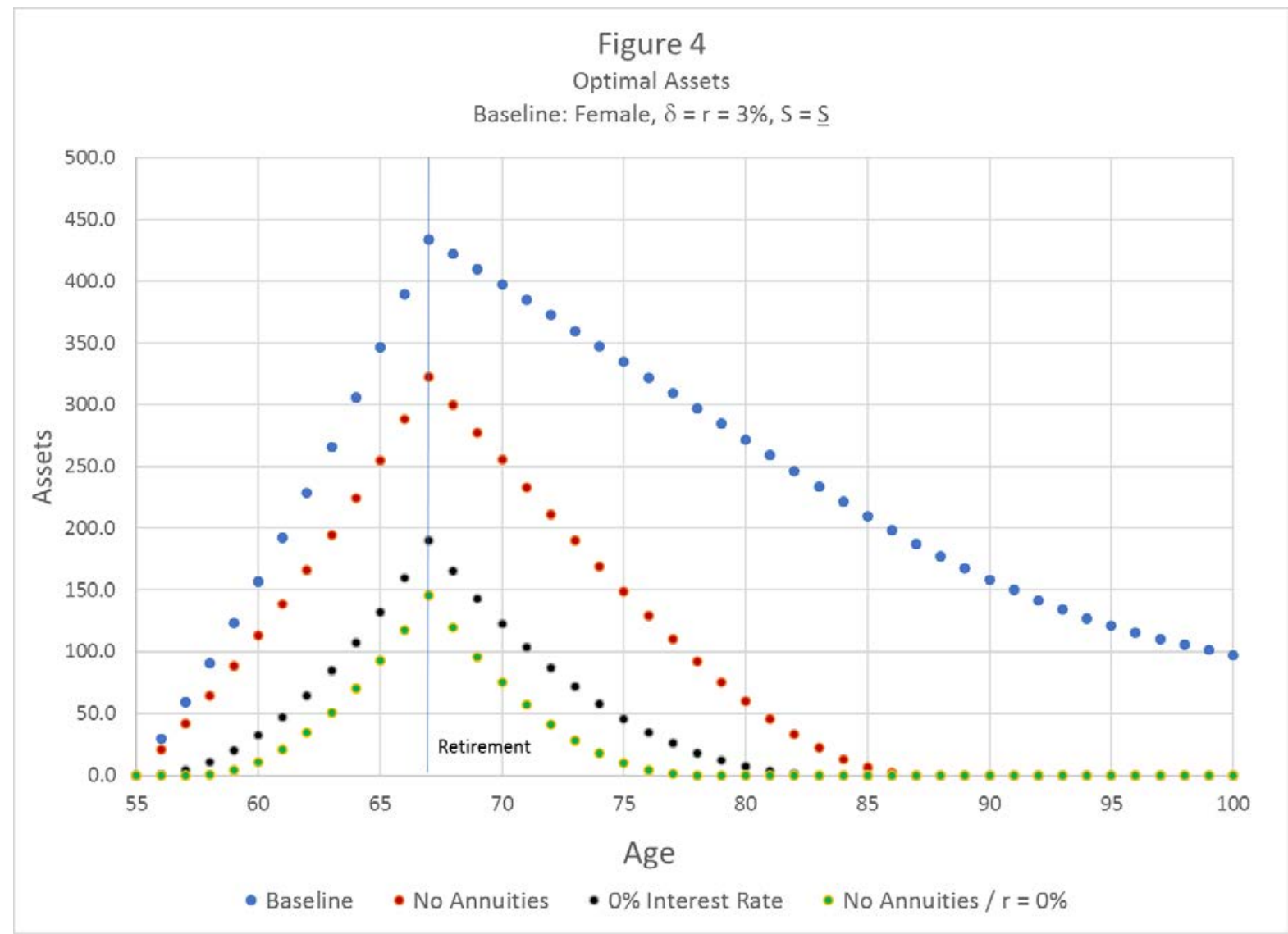


Note that the scenario suggesting retirement wealth of $\$ 145$ (or 1.45 times annual earnings) contains fairly rosy assumptions as it relates to discounting and asset accumulation. The time discount rate is only 3 percent, whereas higher time discounts can easily be motivated. Moreover, the mortality discounting assumes an average female, but men and lower educated individuals tend to have much higher mortality rates. No adjustment for health concerns has yet been made, and the need for saving is fairly high because Social Security is only replacing just over forty percent of income. All of these assumptions suggest a need for fairly high retirement savings, yet the analysis still suggests optimal saving levels are roughly one-third the savings level predicted by full lifetime consumption smoothing.

We solve our model for the three stylized earners described above and summarize our results in Tables 2-4. Each table reports three key statistics: Assets at retirement, consumption at retirement relative to consumption at age 55 , and age when assets are exhausted and consumption is fully reliant on Social Security. Table 2 reports these statistics for the female moderate earners depicted in Figures 2 and 3.

Table 2

Moderate Earnings (43.2\% Replacement) Summary Statitics

\begin{tabular}{|c|c|c|c|c|}
\hline & Baseline & No Annuities & $0 \%$ Interest Rate & No Annuities $/ r=0 \%$ \\
\hline Assets At Retirement (\% baseline) & $\$ 434.03$ & $74.3 \%$ & $43.8 \%$ & $33.5 \%$ \\
\hline Consumption (Age 67 / Age 55) & $100.0 \%$ & $93.0 \%$ & $69.8 \%$ & $69.3 \%$ \\
\hline Age Assets Depleted & 120 & 87 & 83 & 78 \\
\hline
\end{tabular}

Table 3 reports the same statistics for a low earner, who has a 57.6\% Social Security replacement rate. All the other assumptions are the same as they were for the average earner. Even though the low earner's profile is 45 percent as high as the moderate earner in Table 2, 
we once again normalize so that annual earnings are $\$ 100$. Thus, once again, all dollar amounts can be interpreted as percentages of pre-retirement earnings.

Table 3

Low Earnings (57.6\% Replacement) Summary Statitics

\begin{tabular}{|c|c|c|c|c|}
\hline & Baseline & No Annuities & $0 \%$ Interest Rate & No Annuities $/ r=0 \%$ \\
\hline Assets At Retirement (\% baseline) & $\$ 324.00$ & $64.5 \%$ & $29.6 \%$ & $22.7 \%$ \\
\hline Consumption (Age 67 / Age 55) & $100.0 \%$ & $93.0 \%$ & $77.0 \%$ & $76.8 \%$ \\
\hline Age Assets Depleted & 120 & 84 & 77 & 74 \\
\hline
\end{tabular}

Because Social Security replacement rates are higher, the need for retirement savings is reduced in the full smoothing baseline scenario. Assets at retirement now represent only 3.24 times annual income. Adding further discounting has an even larger effect on savings compared to the moderate earner. The 'No Annuities / $r=0 \%$ ' scenario indicates optimal savings levels of only $22.7 \%$ of baseline. Given the relatively high Social Security replacement rate, consumption levels decline more gently pre-retirement to roughly $77 \%$ when interest rates are 0 percent. Assets in retirement are also depleted more quickly. This individual optimally fully relies on Social Security by the age of 74 in the 'No Annuities / $r=0 \%$ ' scenario.

As reported in Table 4, similar trends are apparent for the Very Low Earner who receives approximately an $80 \%$ wage replacement from Social Security.

Table 4

Very Low Earnings (80.0\% Replacement) Summary Statitics

\begin{tabular}{|c|c|c|c|c|}
\hline & Baseline & No Annuities & $0 \%$ Interest Rate & No Annuities / $r=0 \%$ \\
\hline Assets At Retirement ( $\%$ baseline) & $\$ 152.83$ & $39.3 \%$ & $12.1 \%$ & $9.3 \%$ \\
\hline Consumption (Age 67 / Age 55) & $100.0 \%$ & $93.0 \%$ & $88.5 \%$ & $88.2 \%$ \\
\hline Age Assets Depleted & 120 & 77 & 71 & 70 \\
\hline
\end{tabular}


Once again, we have normalized earnings at $\$ 100$ per year, even though actual earnings for very low earners are one-fourth of moderate earners (or about \$13,466 per year in 2019 dollars). For this very low earning woman, baseline wealth at retirement - assuming a 3 percent real interest rate and perfect annuity markets - is 1.53 times annual earnings. That relatively modest optimal nest egg at retirement is reduced by more than 60 percent in the absence of perfect annuity markets and by more than 90 percent with the real interest rate set to zero and no annuity markets. In that later case, optimal retirement wealth is now less than 15 percent of one year's earnings and even that modest amount is spent down in the first three years of retirement. To remove the normalization and give the result in absolute 2019 dollars, the optimal retirement wealth of a very low earner with a zero percent real interest rate and no annuity markets is less than $\$ 2,000$.

All of the results of Tables 2, 3, and 4 are for people with a relatively low 3 percent subjective rate of time preference. Tables $2 \mathrm{~A}$ and $2 \mathrm{~B}$ present the results for moderate earning single women with pure rates of time preference of 5 and 10 percent, respectively. Now, even with the baseline real interest rate of 3 percent and perfect annuity markets, optimal consumption is declining, and optimal retirement wealth is lower than for the case with time preference of 3 percent. For instance, Table 2B shows that with 3 percent real interest rates and a 10 percent rate of time preference, optimal retirement wealth accumulation is less than one year's earnings. Even that small optimal accumulation is significantly reduced if interest rates fall to zero percent. In the case of zero real interest rates and no annuity markets, it is optimal for a moderate earning woman to fully deplete her financial assets other than Social 
Security in her 70s whether her rate of time preference is 3, 5, or 10 percent (see the final column of Tables 2, 2A and 2B).

Assets at Retirement

Consumption (Age 67/Age 55)

Age Assets Depleted
Assets at Retirement

Consumption (Age 67/Age 55)

Age Assets Depleted
Table 2A

Moderate Earnings (43.2\% Replacement) Summary Statistics (female, delta $=5 \%, r=3 \%$, no health discount, annuities available, gamma $=1$ )

$\begin{array}{cccc}\text { Baseline } & \text { No Annuities } & 0 \% \text { Interest Rate } & \text { No Annuities } / r=0 \% \\ \$ 256.70 & 73.2 \% & 45.1 \% & 38.0 \% \\ 78.7 \% & 73.2 \% & 68.3 \% & 68.1 \% \\ 93 & 81 & 77 & 75\end{array}$

Table 2B

Moderate Earnings (43.2\% Replacement) Summary Statistics (female, delta $=10 \%, r=3 \%$, no health discount, annuities available, gamma $=1$ )

$\begin{array}{cccc}\text { Baseline } & \text { No Annuities } & 0 \% \text { Interest Rate } & \text { No Annuities } / \mathrm{r}=0 \% \\ \$ 83.18 & 88.1 \% & 69.5 \% & 63.5 \% \\ 68.30 \% & 67.80 \% & 66.40 \% & 66.10 \% \\ 74 & 73 & 72 & 71\end{array}$

Tables 3A and 3B examine the consequences for low-earning women of rates of time preference of 5 and 10 percent, respectively. Comparing the baseline column of Tables 3 and $3 \mathrm{~B}$, the optimal retirement accumulation is reduced by roughly 88 percent for those with a 10 percent rate of time preference relative to those with a 3 percent time preference.

Table 3A

Low Earnings (57.6\% Replacement) Summary Statistics (female, delta $=5 \%, r=3 \%$, no health discount, annuities available, gamma $=1$ )

$\begin{array}{cccc}\text { Baseline } & \text { No Annuities } & \text { 0\% Interest Rate } & \text { No Annuities } / \mathrm{r}=0 \% \\ \$ 140.27 & 69.5 \% & 41.3 \% & 34.8 \% \\ 79.0 \% & 78.6 \% & 76.1 \% & 75.8 \% \\ 83 & 76 & 73 & 72\end{array}$

Table 3B

Low Earnings (57.6\% Replacement) Summary Statistics 


\begin{tabular}{lcccc} 
& \multicolumn{2}{c}{ (female, delta $=10 \%, r=3 \%$, no health discount, annuities available, gamma $=1$ ) } \\
& Baseline & No Annuities & $0 \%$ Interest Rate & No Annuities $/ \mathrm{r}=0 \%$ \\
Assets at Retirement & $\$ 41.27$ & $89.5 \%$ & $69.0 \%$ & $63.5 \%$ \\
Consumption (Age 67/Age 55) & $75.6 \%$ & $75.3 \%$ & $74.0 \%$ & $73.7 \%$ \\
Age Assets Depleted & 71 & 71 & 70 & 70
\end{tabular}

Switching to a zero percent interest regime further reduces accumulated savings at retirement.

Once again, optimal retirement wealth is really quite low. In 2019 dollars, the figure is approximately $\$ 6,000$ with zero percent interest rates.

For very low earners - with Social Security replacement rates of 80 percent of preretirement earnings - optimal wealth at retirement is basically zero when the rate of time preferences is above 3 percent. These results are not shown.

\section{Delaying Social Security, Annuity Demand and Time Discounting}

There is a large, recent literature on the best age at which to commence Social Security retirement benefits (see, for example, Meyer and Reichenstein 2010; Sass, Sun and Webb 2013; and Shoven and Slavov 2014a,b). The general finding is that with today's low real interest rates and the improved mortality risks of the last thirty years or so, deferring the claiming of Social Security retirement benefits is actuarially advantageous for most people. That is, the expected present value of the increased future benefits exceeds the present value of the foregone benefits inherent in a deferral strategy. The net expected present value of deferring can be quite high. Despite this, relatively few people defer benefits beyond the normal retirement age (soon to be 67).

This paper offers a possible explanation, at least for those who are in the bottom half of the earnings distribution during their working lives. The additional Social Security benefits achieved 
via deferral come in the form of an incremental inflation-indexed life annuity. While this form of income is desirable for individuals aiming for constant consumption in retirement, it is distinctly sub-optimal for those whose optimal consumption pattern declines with age. One cannot borrow against future Social Security benefits, so much of the incremental Social Security receipts can only increase consumption at an age where relatively low consumption is desired. If the gains from deferring Social Security were paid as a lump sum payment upon commitment to defer, the participant could allocate the additional wealth in such a way as to finance greater incremental consumption early in retirement and lesser incremental consumption late in retirement. Given time preference and the mortality and morbidity considerations we have covered in this paper, individuals may prefer a front loaded payoff from Social Security rather than an inflation-indexed life annuity. This sub-optimal pattern of incremental Social Security benefits from deferral may be sufficiently unattractive to make the whole deferral option unappealing. This phenomenon may explain why individuals report greater willingness to delay claiming if the gains from delay are paid as a lump sum (Maurer et al. 2016).

The same argument does not apply to most people in the upper half of the earnings distribution. The Social Security replacement rate is lower for them, and exhausting retirement wealth before death is usually not part of their optimal plan. Therefore they can rearrange their withdrawals from retirement savings to achieve their optimal consumption plan and still benefit from the higher Social Security benefits achieved via deferral.

Similarly, the considerations in this paper may help to explain the lack of demand for private annuities (e.g., Mitchell et al. 1999; Warner and Pleeter 2001). Spending liquid assets for 
annuities whose payout pattern does not correspond with optimal consumption isn't particularly attractive. It is well known that private annuity markets suffer from adverse selection. Adding a sub-optimal pattern of payouts further reduces the attractiveness of annuities, especially for those in the lower part of the income distribution.

\section{Conclusions}

In this paper, we have shown that in a zero real interest rate environment, the optimal pattern of consumption is declining with age. The reason is simple: the market return to patience is zero and most everyone displays some degree of positive time preference. We argue that mortality risk and health risk, particularly dementia, steepen the negative slope of optimal consumption for people in their retirement years. If this zero-interest rate regime - which has existed for more than a decade now and shows no sign of changing - persists, then the optimal amount of wealth to accumulate for retirement is significantly diminished. In fact, for very low earners, with Social Security replacement rates of 80 percent, zero retirement savings or close to it is optimal. For those with low or moderate earnings histories, the savings target at retirement is greatly reduced by the zero real interest rate environment and the lack of perfect annuity markets. For them, the optimal plan typically is to spend down their retirement savings in the first three to ten years of retirement (depending on their subjective rate of time preference) and then live on Social Security alone after that.

A large fraction of retirees depend on Social Security for the bulk of their retirement income. ${ }^{7}$ Our analysis suggests that this phenomenon may not be a symptom of widespread

\footnotetext{
${ }^{7}$ See https://www.ssa.gov/news/press/factsheets/basicfact-alt.pdf.
} 
undersaving for retirement. Rather, it may be due to the relative generosity of Social Security, the form in which Social Security is paid (as a real annuity), and the extremely low safe rate of return on retirement assets. Our results suggest that standard financial planning advice, which centers on constant consumption during retirement, is inconsistent with a life cycle model, particularly in the current low-interest rate environment.

We have yet to fully explore the consequences of different degrees of risk aversion and different discounts for poor health among the very elderly. We expect that health discounting will strengthen the finding that declining consumption is optimal, and that this finding will be robust to the choice of risk aversion parameter.

\section{References}

Attanasio, O. P., \& Weber, G., "Consumption and Saving: Models of Intertemporal Allocation and Their Implications for Public Policy," Journal of Economic Literature, 48(3), 2010, pp. 693-751. https://doi.org/http://www.aeaweb.org/jel/index.php

Bernheim, B. Douglas, Jonathan Skinner and Steven Weinberg, "What Accounts for the Variation in Retirement Wealth among U.S. Households?" American Economic Review, Volume 91, Number 4, September 2001, pp. $832-857$.

Brown, Jeffrey R., Jeffrey B. Liebman, and Joshua Pollet.. "Estimating Life Tables that reflect socioeconomic differences in mortality." In Feldstein, Martin and Liebman, Jeffrey B. (eds), The Distributional Aspects of Social Security and Social Security Reform, Chicago: University of Chicago Press, 2002.

Chetty, Raj, Michael Stepner, Sarah Abraham, Shelby Lin, Benjamin Scuderi, Nicholas Turner, Augustin Bergeron, and David Cutler, "The Association Between Income and Life Expectancy in the United States, 2001-2014." Journal of the American Medical Association, 315(16), 2016, pp. 1750-1766.

Clingman, Michael, Kyle Burkhaler, and Chris Chaplain, "Replacement Rates for Hypothetical Retired Workers." Social Security Administration. Actuarial Note 2019.9. 
Cohen, Jonathan D., Keith Marzilli Ericson, David Laibson and John Myles White, "Measuring Time Preferences." NBER Working Paper No. 22455, July 2016 (revised February 2019)

Delavande, Adeline and Susann Rohwedder, "Differential Survival in Europe and the United States: Estimates Based on Subjective Probabilities of Survival." Demography, Volume 8, 2011, pp. 1377-1400.

Fuchs, Victor R., "Time Preference and Health: An Exploratory Study," in Economic Aspects of Health, Victor Fuchs, Ed., University of Chicago Press, 1982, pp. 93-120. Also, appeared as NBER Working Paper No. 539, August 1980.

Ghilarducci, T., M. Papadopoulos and A. Webb, "Inadequate Retirement Savings for Workers Nearing Retirement," Schwartz Center for Economic Policy Analysis and Department of Economics, The New School for Social Research, Policy Note Series, 2017

Goda, Gopi, Shanthi Ramnath, John B. Shoven, and Sita Nataraj Slavov, "The Financial Feasibility of Delaying Social Security: Evidence from Administrative Tax Data." Journal of Pension Economics and Finance 17(4), 2018, pp. 419-436.

Goda, Gopi Shah, Matthew R. Levy, Colleen Flaherty Manchester, Aaron Sojourner, and Joshua Tasoff, "The Role of Time Preferences and Exponential-Growth Bias in Retirement Savings." NBER WP 21482, August 2015.

Gomes, Francisco, Kenton Hoyem, Wei Hu and Enrichetta Ravina, "Retirement Savings Adequacy in United States Defined Contribution Plans, Kellogg School of Management Working Paper, November 2018.

Gourinchas, Pierre Olivier and Jonathan Parker, "Consumption over the Life Cycle," Econometrica, Volume 70, Number 1, January 2002, pp. 47-89.

Hammermesh, Daniel S., "Consumption during Retirement: The Missing Link in the Life Cycle," Review of Economics and Statistics, Volume 66, No. 1, 1984, pp. 1-7.

Hausman, Jerry A., "Individual Discount Rates and the Purchase and Utilization of Energy-Using Durables," Bell Journal of Economics, Volume 10, Number 1, Spring 1979, pp. 33-54.

Huffman, David, Raimund Maurer and Olivia S. Mitchell, "Time Discounting and Economic Decision Making Among the Elderly," NBER Working Paper No. 22438, July 2016.

Hurd, Michael D., James P. Smith, and Julie M. Zissimopoulos, "The Effects of Subjective Survival on Retirement and Social Security Claiming." Journal of Applied Econometrics 19 (6), 2004, pp. 761-775. 
Hurd, Michael D., “Mortality Risks and Bequests," Econometrica, Volume 57, Number 4, July 1989, pp. $779-813$.

Hurd, Michael D. and Susann Rohwedder, "The Retirement Consumption Puzzle: Anticipated and Actual Declines in Spending at Retirement," NBER Working Paper \#9586, March 2003.

Hurd, Michael D. and Susann Rohwedder, "Some Answers to the Retirement Consumption Puzzle," NBER Working Paper \#12057, February 2006.

Hurst, Eric, "The Retirement of a Consumption Puzzle," NBER Working Paper \#13789, February 2008.

Kotlikoff, L.J., "Is Conventional Financial Planning Good for Your Financial Health?” Unpublished draft, 2006. Retrieved from http://people.bu.edu/kotlikof/Financial\%20Health\%201-11061.pdf

Laubach, Thomas and John C. Williams, "Measuring the Natural Rate of Interest," Review of Economics and Statistics, Volume 85, No. 4, November 2003, pp. 1063-70.

Maurer Raimond, Olivia S. Mitchell, Ralph Rogalla, and Tatjana Schimetschek, "Will They Take the Money and Work? People's Willingness to Delay Claiming Social Security Benefits for a Lump Sum." Journal of Risk and Insurance, 85(4), 2018, pp. 871-1126.

Meyer, William, and William Reichenstein, "Social Security: When to Start Benefits and How to Minimize Longevity Risk." Journal of Financial Planning, 23 (3), 2010, pp. 49-59.

Meyer, William, and William Reichenstein, "Social Security Claiming Strategies for Singles." Retirement Management Journal, 2 (3), 2012, pp. 61-66.

Mitchell, Olivia S., James M. Poterba, Mark J. Warshawsky, and Jeffrey R. Brown, "New Evidence on the Money's Worth of Individual Annuities." American Economic Review, 89 (5), 1999, pp. 1,299-1,318.

Sass, Steven A., Wei Sun, and Anthony Webb, "Social Security Claiming Decision of Married Men and Widow Poverty." Economics Letters, 119 (1). 2013, pp. 20-23.

Scott, Jason, John B. Shoven, Sita Slavov, and John G. Watson, "Retirement Implications of a Low Wage Growth, Low Real Interest Rate Economy, NBER Working Paper No. 25556, February 2019.

Scholz, J. K., \& Seshadri, A., "What Replacement Rates Should Households Use?” (No. WP 2009214). Michigan Retirement Research Center, 2009. Retrieved from https://deepblue.lib.umich.edu/bitstream/handle/2027.42/65069/wp214.pdf 
Shefrin, Hersh M. and Richard H. Thaler, "The Behavioral Life-Cycle Hypothesis," Economic Inquiry, 26(4), 1988, pp. 609-643.

Shoven, John, and Sita Slavov. 2014a. "Does It Pay to Delay Social Security?" Journal of Pension Economics and Finance, 13 (2): 121-144.

Shoven, John, and Sita Slavov. 2014b. "Recent Changes in the Gains from Delaying Social Security." Journal of Financial Planning, 27 (3): 32-41.

Siegel, Michele, Elizabeth H. Bradley, and Stanislav V. Kasl. 2003. "Self-rated life expectancy as a predictor of mortality: evidence from the HRS and AHEAD surveys." Gerontology, 49(4):265-71.

Simon, Curtis J., John T. Warner and Saul Pleeter, "Discounting, Cognition, and Financial Awareness: New Evidence from a Change in the Military Retirement System," Economic Inquiry, Volume 53, Issue 1, January 2015, pp. 318-334.

Warner, John T. and Saul Pleeter, "The Personal Discount Rate: Evidence from Military Downsizing Programs," American Economic Review, Volume 91, Number 1, March 2001, pp. 33-53.

Yaari, Menahem E. 1965. "Uncertain Lifetime, Life Insurance, and the Theory of the Consumer." Review of Economic Studies, 32 (2): 137-150. 